\title{
Kinetics of COS with Primary and Secondary Amines in Aqueous Solutions
}

\author{
R. J. Littel, G. F. Versteeg, and W. P. M. van Swaaij \\ Dept. of Chemical Engineering, University of Twente, 7500 AE Enschede, The Netherlands
}

The reaction between $C O S$ and aqueous solutions of primary and secondary amines has been studied by means of the stirred cell technique. Kinetic experiments at temperatures 283 to $333 \mathrm{~K}$ were carried out with MEA, DGA, DEA, DIPA, MMEA, $A M P$, and MOR. All kinetic experiments could be described by a zwitterion reaction mechanism similar to the mechanism proposed by Caplow (1968) for the reaction between $\mathrm{CO}_{2}$ and secondary amines:

$$
\begin{gathered}
\mathrm{COS}+\mathrm{R}_{2} \mathrm{NH} \mathrm{R}_{2} \mathrm{NH}^{+} \mathrm{COS}^{-} \\
\mathrm{R}_{2} \mathrm{NH}^{+} \mathrm{COS}^{-}+\mathrm{B} \leftrightarrow \mathrm{R}_{2} \mathrm{NCOS}^{-}+\mathrm{BH}^{+}
\end{gathered}
$$

Analysis of concentrated amine solutions at high $\operatorname{COS}$ concentrations by various analytical techniques confirmed the conclusions from the kinetic experiments. For all amines except for MEA, the overall reaction rate was found to be determined entirely by the zwitterion deprotonation rate.

\section{Introduction}

In process industry, basic alkanolamine solutions are used frequently to remove acidic components such as $\mathrm{H}_{2} \mathrm{~S}, \mathrm{COS}$, and $\mathrm{CO}_{2}$, from natural and refinery gases. Industrially important alkanolamines for this operation are the primary amines monoethanolamine (MEA) and diglycolamine (DGA), the secondary amines diethanolamine (DEA) and diisopropanolamine (DIPA), and the tertiary amine $\mathrm{N}$-methyldiethanolamine (MDEA). Usually these alkanolamines are applied in aqueous solutions, but combined solvents like water and sulfolane in the Shell Sulfinol process are used also (Kohl and Riesenfeld, 1985). Much research has been focused on the selective absorption of sulfur compounds, particularly $\mathrm{H}_{2} \mathrm{~S}$, because simultaneous removal of $\mathrm{CO}_{2}$ often is not preferred both from technical and economical points of view.

The reaction between $\mathrm{H}_{2} \mathrm{~S}$ and alkanolamines can be considered instantaneous with respect to mass transfer, whereas the reaction between $\mathrm{CO}_{2}$ and alkanolamines is a finite rate reaction. Consequently, improvement of $\mathrm{H}_{2} \mathrm{~S}$ selectivity can, among others, be achieved by applying an alkanolamine which reacts relatively slow with $\mathrm{CO}_{2}$. This explains the increasing

Present address of R. J. Littel: Koninklijke/Shell Laboratorium Amsterdam, P.O. Box 3003, 1003 AA Amsterdam, The Netheriands. popularity of tertiary and sterically hindered (secondary) alkanolamines for selective $\mathrm{H}_{2} \mathrm{~S}$ absorption. However, COS reacts much slower with alkanolamines than $\mathrm{CO}_{2}$. As a result, an increase in $\mathrm{H}_{2} \mathrm{~S}$ selectivity is usually accompanied by a decrease in COS absorption capacity. Eventually, the attainable sulfur selectivity is limited by this decrease in COS removal because the treating target is a total sulfur specification. Obviously, thorough knowledge of reaction mechanism and kinetics for the reaction between $\operatorname{COS}$ and alkanolamines is necessary for an adequate design of gas treating plants.

Data for the reaction of COS with primary and secondary alkanolamines are very scarce in literature. Sharma (1965) presented some kinetic data for $\mathrm{CO}_{2}$ and $\mathrm{COS}$ with various amines and concluded that $\mathrm{CO}_{2}$ and $\mathrm{COS}$ follow similar reaction mechanisms, with COS reacting about a factor 100 slower. He, however, carried out kinetic experiments at only one amine concentration. Recently, Singh and Bullin (1988) reported some data for the reaction between COS and DGA over a temperature range of 307 to $322 \mathrm{~K}$. From their experiments they concluded that the overall reaction rate was first order in the COS concentration and first order in the DGA concentration.

In the present work, the reaction of COS with primary and secondary amines has been studied extensively by means of 
the stirred cell reactor technique. Kinetic experiments at temperatures ranging from 283 to $333 \mathrm{~K}$ were carried out with aqueous solutions of MEA, DGA, DEA, DIPA, methylmonoethanolamine (MMEA), 2-amino-2-methyl-1-propanol (AMP), and morpholine (MOR). Amine solutions at high COS loadings were analyzed with various analytical techniques to provide additional confirmation for the findings from the $\mathrm{ki}$ netic experiments.

\section{Literature}

The reaction of COS with primary and secondary amines in aqueous solutions has received very little attention in literature. Sharma (1965) carried out absorption experiments of $\mathrm{CO}_{2}$ and $\mathrm{COS}$ into aqueous solutions of various amines at $298 \mathrm{~K}$ and concluded from his experiments that $\mathrm{CO}_{2}$ and $\mathrm{COS}$ react similarly with amines. He observed a reaction rate for $\mathrm{COS}$ which was about a factor 100 lower than that for $\mathrm{CO}_{2}$. Although the experiments of Sharma (1965) seem valid, it should be noted that for each amine experiments were carried out at only one concentration $\left(1,000 \mathrm{~mol} \cdot \mathrm{m}^{-3}\right)$.

Recently, Singh and Bullin (1988) reported kinetic data for the reaction of COS with aqueous solutions of diglycolamine over a temperature range of 307 to $322 \mathrm{~K}$. They carried out absorption experiments in a continuously operated gas-liquid contactor which was designed to simulate a single tray in an absorption column. COS and other components in the amine solutions were analyzed by means of a GC technique. From their experiments, Singh and Bullin (1988) concluded that the overall reaction was single order in both the COS and amine concentrations. Their interpretation method, however, did not allow for broken reaction orders.

Rahman et al. (1989) analyzed anhydrous amines loaded with $\mathrm{COS}$ by means of ${ }^{1} \mathrm{H}$ and ${ }^{13} \mathrm{C}$ NMR. From their spectra they concluded that thiocarbamates were formed in the case of MEA, DEA and DGA, whereas the thiocarbamate salt of DIPA could not be positively. ascertained. However, some remarks must be presented with respect to the work of Rahman et al. (1989). It is probably not completely correct to compare spectra for pure amine and loaded amine to each other if these spectra have been obtained with different solvents: in general, the place of a peak and even the occurrence of a peak may differ considerably for different solvents. Moreover, the large difference in noise level between ${ }^{13} \mathrm{C}$ NMR spectra for pure amines and those for loaded amines seems peculiar and may even lead to artificial peaks.

Experimental work on the cleavage of monothiocarbamates (Ewing et al., 1980; Millican et al., 1983) suggests a zwitterion mechanism for the reaction between $\operatorname{COS}$ and primary and secondary amines. For the reaction of $\mathrm{CO}_{2}$ with these amines, the zwitterion mechanism is widely accepted (see, for example, Caplow, 1968; Danckwerts, 1979; Blauwhoff et al., 1984; Versteeg and van Swaaij, 1988a, Versteeg and Oyevaar, 1989; Littel et al., 1992a,b). In the case of COS, a zwitterion reaction mechanism would be given by Eqs. 1 and 2 .

$$
\begin{aligned}
& \mathrm{COS}+\mathrm{R}_{2} \mathrm{NH}_{k_{-1}}^{\stackrel{k_{2}}{\leftrightarrow}} \mathbf{R}_{2} \mathrm{NH}^{+} \mathrm{COS}^{-} \\
& \mathrm{R}_{2} \mathrm{NH}^{+} \mathrm{COS}^{-}+\underset{k_{-b}}{\stackrel{k_{b}}{\longrightarrow}} \mathrm{R}_{2} \mathrm{NCOS}^{-}+\mathrm{BH}^{+}
\end{aligned}
$$

This mechanism comprises two steps: formation of the COS- amine zwitterion (reaction 1), followed by base-catalyzed deprotonation of this zwitterion (reaction 2). In principle, any base present in solution will contribute to the deprotonation of the zwitterion.

Considering the very limited information in open literature, additional experimental information is necessary to determine the validity of the zwitterion mechanism for the reaction between COS and primary and secondary amines. Therefore, in the present work kinetic experiments at various temperatures were carried out with aqueous solutions of various primary and secondary amines.

\section{Experimental Studies}

All kinetic experiments were carried out in a thermostatted stirred cell reactor with a flat, horizontal gas-liquid interface. The stirred-cell reactor was operated batchwise with respect to both gas and liquid phase. The pressure decrease, measured by a pressure transducer which was connected to an Apple IIe computer, was recorded as a function of time. Experimental setup and procedure have been described in more detail by, for example, Blauwhoff et al. (1984).

Based on mass balances for both gas and liquid phase, the following expression for the carbonyl sulfide flux can be derived:

$$
J_{\mathrm{Cos}}=m_{\mathrm{Cos}} k_{L, \cos } E \frac{P_{\mathrm{Cos}}}{R T}
$$

The enhancement factor $E$ is equal to $H a$ if pseudo-first-order conditions are fulfilled:

$$
3<H a \ll E^{\infty}
$$

with:

$$
\begin{gathered}
H a=\frac{\sqrt{k_{o v} D_{\mathrm{COS}}}}{k_{L, \cos }} \\
E^{\infty}=\sqrt{\frac{D_{\mathrm{COS}}}{D_{\mathrm{R}_{2} \mathrm{NH}}}}+\sqrt{\frac{D_{\mathrm{R}_{2} \mathrm{NH}}}{D_{\mathrm{COS}}}} \frac{\left[\mathrm{R}_{2} \mathrm{NH}\right] R T}{\gamma m_{\mathrm{COS}} P_{\mathrm{COS}}}
\end{gathered}
$$

The reaction between COS and amines is reversible and, strictly speaking, Eq. 6 is valid only for irreversible reactions. However, low amine conversions in combination with high equilibrium constants as encountered in the present work validate sufficiently the application of Eq. 6. The observed reaction rates and the applied COS pressures were low and, consequently, condition 4 could be fulfilled easily. From the work of Thompson et al. (1935) and Philipp and Dautzenberg (1965), it could be concluded that the contribution of the reaction between $\mathrm{COS}$ and $\mathrm{OH}^{-}$to the overall reaction rate was negligible.

Since COS reacts with amine solutions, it is not possible in general to determine its solubility and diffusivity directly. The COS solubility was determined based on a $\operatorname{COS}-\mathrm{N}_{2} \mathrm{O}$ analogy (Littel et al., 1992c). The diffusivity of COS in amine solutions can be obtained from the COS diffusivity in water using the modified Stokes-Einstein relationship reported by Versteeg and van Swaaij (1988b). Since no reliable data on the temperature 
Table 1. Viscosity and $\mathrm{N}_{2} \mathrm{O}$ Solubility Data for Aqueous Amine Solutions at $283 \mathrm{~K}$

\begin{tabular}{|c|c|c|c|c|c|c|c|c|}
\hline \multicolumn{3}{|c|}{ MEA } & \multicolumn{3}{|c|}{ DGA } & \multicolumn{3}{|c|}{ DEA } \\
\hline$\underset{\left[\mathrm{mol} \cdot \mathrm{m}^{-3}\right]}{[\mathrm{MEA}]}$ & {$\left[10^{3} \stackrel{\eta}{\mathrm{Pa} \cdot \mathrm{s}}\right]$} & $m_{\mathrm{N}_{2} \mathrm{O}}$ & $\begin{array}{c}{[\mathrm{DGA}]} \\
{\left[\mathrm{mol} \cdot \mathrm{m}^{-3}\right]}\end{array}$ & {$\left[10^{3} \stackrel{\eta}{\mathrm{Pa} \cdot \mathrm{s}}\right]$} & $m_{\mathrm{N}_{2} \mathrm{O}}$ & $\begin{array}{c}{[\mathrm{DEA}]} \\
{\left[\mathrm{mol} \cdot \mathrm{m}^{-3}\right]}\end{array}$ & $\begin{array}{c}\eta \\
{\left[10^{3} \mathrm{~Pa} \cdot \mathrm{s}\right]}\end{array}$ & $m_{\mathrm{N}_{2} \mathrm{O}}$ \\
\hline 194 & 1.36 & & 218 & 1.41 & & 187 & 1.41 & \\
\hline 204 & & 0.877 & 199 & & 0.900 & 210 & & 0.886 \\
\hline 206 & & 0.891 & 200 & & 0.897 & 212 & & 0.868 \\
\hline 393 & 1.41 & & 408 & 1.51 & & 372 & 1.55 & \\
\hline 391 & & 0.892 & 435 & & 0.860 & 387 & & 0.879 \\
\hline 392 & & 0.882 & 437 & & 0.890 & 389 & & 0.882 \\
\hline 789 & 1.53 & & 795 & 1.76 & & 760 & 1.79 & \\
\hline 782 & & 0.881 & 847 & & 0.849 & 761 & & 0.874 \\
\hline 782 & & 0.864 & 847 & & 0.855 & 767 & & 0.859 \\
\hline 1,588 & 1.81 & & 1,555 & 2.39 & & 1,532 & 2.52 & \\
\hline 1,619 & & 0.864 & 1,667 & & 0.800 & 1,536 & & 0.834 \\
\hline 1,621 & & 0.869 & 1,676 & & 0.771 & 1,541 & & 0.840 \\
\hline 2,414 & 2.17 & & 2,463 & 3.57 & & 2,393 & 3.84 & \\
\hline 2,422 & & 0.844 & 2,527 & & 0.719 & 2,367 & & 0.778 \\
\hline 2,425 & & 0.832 & 2,553 & & 0.715 & 2,373 & & 0.778 \\
\hline 3,243 & 2.63 & & 3,332 & 4.99 & & 3,265 & 6.17 & \\
\hline 3,162 & & 0.819 & 3,112 & & 0.671 & 3,161 & & 0.717 \\
\hline 3,163 & & 0.811 & 3,147 & & 0.663 & 3,169 & & 0.705 \\
\hline
\end{tabular}

dependence are available in literature, the COS diffusivity in water at various temperatures was estimated from the COS diffusivity at $298 \mathrm{~K}$ reported by Littel et al. (1992c), assuming the same activation energy as reported by Versteeg and Swaaij (1988b) for $\mathrm{CO}_{2}$. Viscosity and $\mathrm{N}_{2} \mathrm{O}$ solubility data for amine solutions used in the present work are presented in Table 1 or were reported by Littel et al. (1992c).

For all kinetic experiments, COS pressures and amine loadings were typically $0.001-0.010 \mathrm{MPa}$ and $1-10 \%$, respectively.

MEA, DEA, MMEA, AMP, and MOR were obtained from Janssen Chimica, DIPA was obtained from Riedel-de Haën, and DGA was provided by Texaco Chemical Company. All amines were at least $99 \%$ pure and used as received. COS with a minimum purity of $97.5 \%$ was obtained from UCAR.

\section{Results}

\section{Kinetic Experiments}

The reaction between $\operatorname{COS}$ and the primary alkanolamines

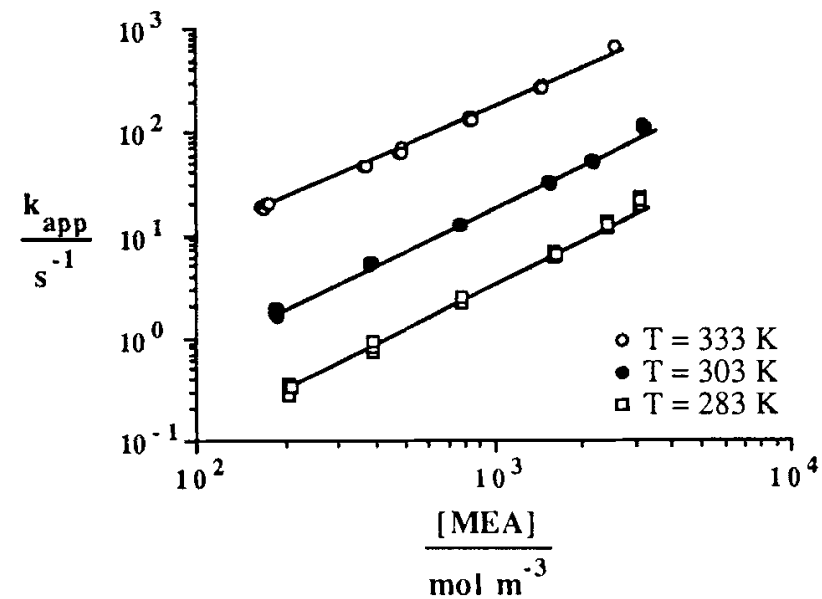

Figure 1. Experimental results for aqueous MEA solutions.
MEA and DGA has been studied in aqueous solutions as a function of temperature. For MEA, kinetic experiments were carried out at 283,303 and $333 \mathrm{~K}$; the reaction of COS with DGA was studied at 283,303 and $318 \mathrm{~K}$. The experimental data are presented in Figures 1 and 2 for MEA and DGA, respectively. These figures show that a broken reaction order in amine was observed for all temperatures investigated. This reaction order in amine was found to be unaffected by temperature within experimental accuracy. For MEA the reaction order in amine was about 1.4, whereas for DGA is was about 1.6. The experimental data in Figures 1 and 2 show a definite influence of temperature on the overall reaction rate.

The reaction between $\operatorname{COS}$ and various secondary amines has been investigated in aqueous solutions. The reaction of COS and DEA was studied at 283, 303 and $333 \mathrm{~K}$, whereas kinetic experiments of COS with DIPA, MMEA, AMP, and MOR were carried out at $303 \mathrm{~K}$. The measured overall reaction rate constants are plotted against the amine concentration in Figures 3 to 5 . For all secondary amines investigated, a reaction order in amine of almost 2 was observed. The overall reaction

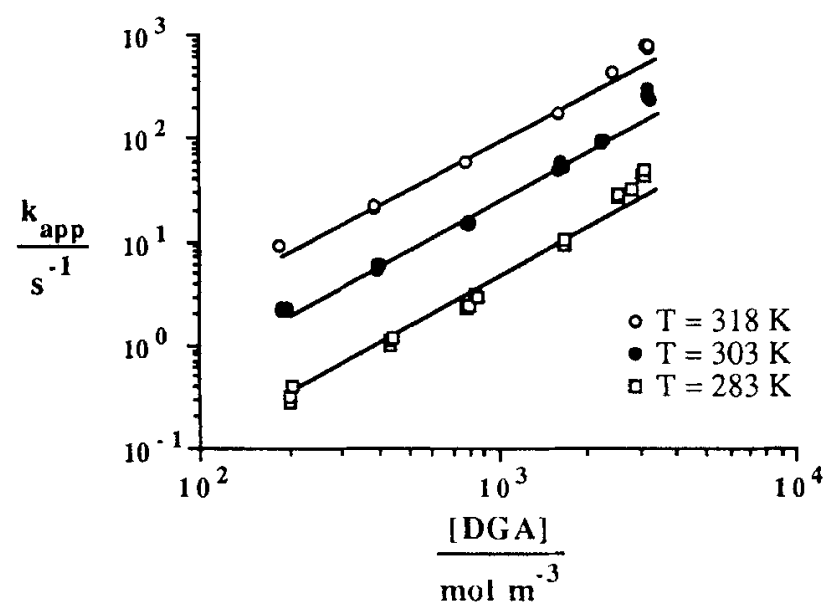

Figure 2. Experimental results for DGA solutions. 


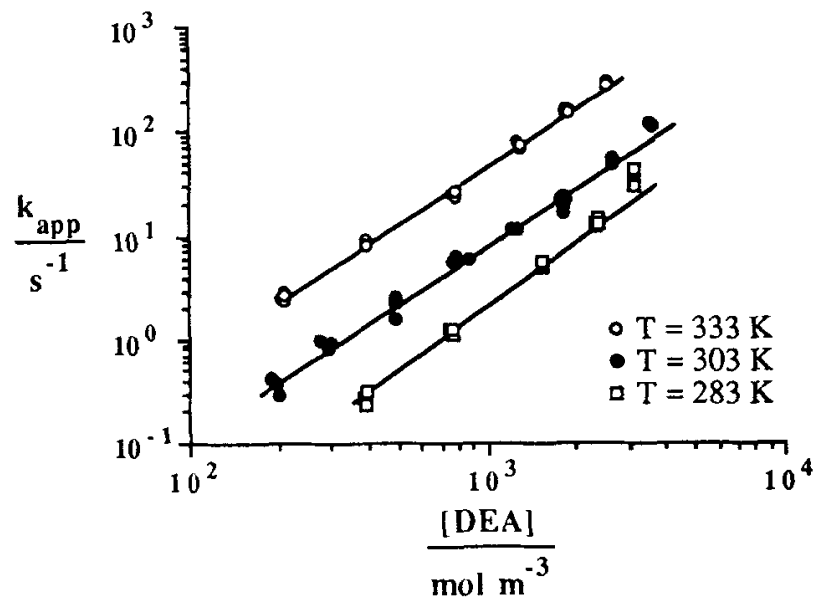

Figure 3. Experimental results for aqueous DEA solutions.

rate of COS with DEA showed a significant dependence on temperature.

Close inspection of Figures 1 to 5 shows that the observed first-order apparent reaction rate constants deviate systematically at the highest amine concentrations. This must probably be attributed to a tendency of the $\mathrm{COS}-\mathrm{N}_{2} \mathrm{O}$ analogy to underestimate the COS solubility at higher amine concentrations. Littel et al. (1992c) showed for aqueous ethyleneglycol and aqueous sulfolane solutions that this $\operatorname{COS}-\mathrm{N}_{2} \mathrm{O}$ analogy is valid only for dilute aqueous solutions up to about $20 \mathrm{wt}$. $\%$. For the present kinetic experiments, this limit appears to have been violated at the highest amine concentrations for the bulkier amines. Therefore, these experiments were not taken into account in the calculation of kinetic rate constants from the observed overall rate constants.

For all amines investigated, a reaction order in amine between 1 and 2 has been observed. From the COS pressure decrease as a function of time, it could be concluded that the reaction order in COS was 1 . These observed reaction orders can be described by the zwitterion reaction mechanism (reactions 1 and 2), and apparently the overall reaction rate is, at least partially, determined by the zwitterion deprotonation

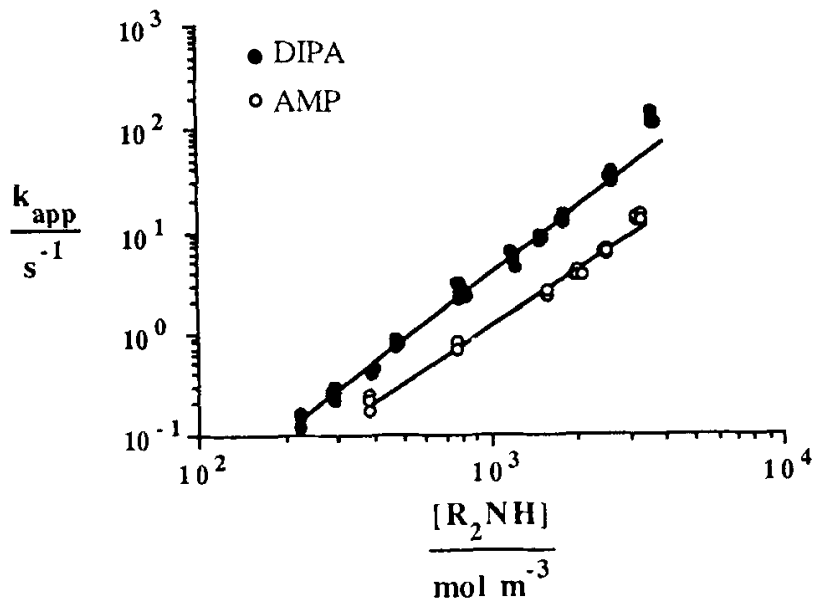

Figure 4. Experimental results for aqueous DIPA and AMP solutions at $303 \mathrm{~K}$.

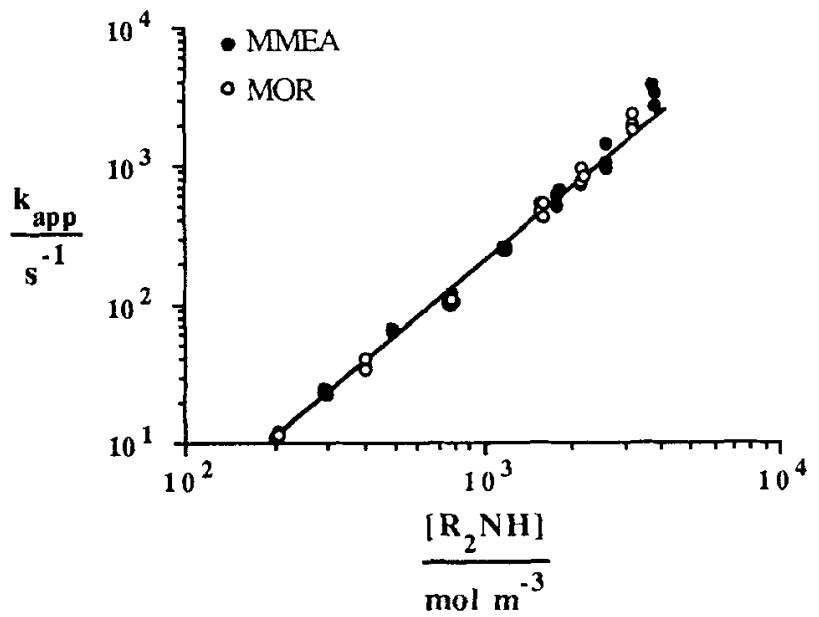

Figure 5. Experimental results for aqueous MMEA and MOR solutions at $303 \mathrm{~K}$.

rate. The overall reaction rate was found to increase with increasing basic strength of the alkanolamine for the amines with similar compositions (MEA, DGA, DEA, DIPA, and MMEA). Compared to these amines, the sterically hindered amine AMP reacts much slower than expected from its basic strength whereas the cyclic amine MOR reacts much faster.

\section{Chemical analyses}

To obtain additional confirmation for the findings of the kinetic experiments, amine samples with about $10 \mathrm{wt} . \%$ water were heavily loaded with $\operatorname{COS}(2-10 \mathrm{wt} . \% \mathrm{~S})$ and analyzed by means of chemical analysis techniques. Techniques used were: ${ }^{1} \mathrm{H}$ and ${ }^{13} \mathrm{C}$ NMR, GLC, MS and element analysis.

GLC and NMR analysis of the loaded MEA and MMEA samples showed significant amounts of degradation products. For MEA, the observed degradation products were well in line with the degradation mechanism suggested by Pearce et al. (1961) and Berlie et al. (1965). In the case of MMEA, the degradation products could not be identified. For DEA and AMP, no significant differences between NMR spectra for loaded and unloaded samples were observed. All these observations seem to agree with the proposed zwitterion reaction mechanism, because the NMR technique is rather insensitive to differences between reactants and products postulated by this mechanism.

In loading the MOR sample with COS, a white salt crystallized, which was well soluble in water. The MS spectrum of this salt showed a peak with a bruto molecular weight of 147 , which corresponded to a bruto molecule formula of $\mathrm{C}_{5} \mathrm{H}_{9} \mathrm{NSO}_{2}$. Element analysis of the water-free salt yielded a bruto molecule formula of $\mathrm{C}_{8.7} \mathrm{H}_{16.1} \mathrm{~N}_{1.9} \mathrm{SO}_{2.9}$. The NMR spectra of this salt solved in $\mathrm{D}_{2} \mathrm{O}$ showed the presence of a loosely bound complex, which could not be identified unambiguously. The analysis by means of GLC showed only MOR, probably as a result of disintegration of the salt due to the conditions applied in GLC. Considering all chemical analyses, the most likely composition of the obtained salt is presented in Figure 6, which shows a complex of thiocarbamate and protonated amine. In loading a MOR sample with $\mathrm{CO}_{2}$ also a white salt crystallized, and analysis of this salt indicated a similar composition as that given in Figure 6. 


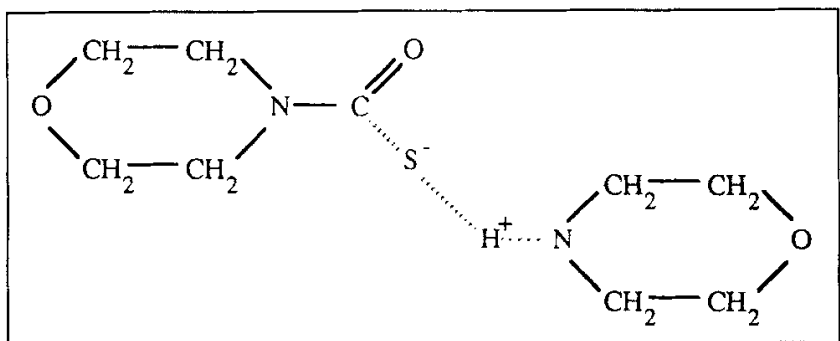

Figure 6. Composition of crystallization product from concentrated MOR solution at high COS con. centrations.

In summarizing the results from the analysis of amine samples heavily loaded with $\mathrm{COS}$, it can be concluded that no evidence was obtained which contradicts the zwitterion mechanism, whereas the observations for MOR clearly support this mechanism. Since MEA and MMEA were shown to be strongly susceptible to degradation by $C O S$, they seem to be unsuitable for COS removal. This susceptibility to degradation by COS did not hamper the kinetic experiments with MEA and MMEA, as only low amine conversions were applied and fresh amine solutions were used in those experiments.

\section{Discussion}

The kinetic experiments and the analysis of aqueous amine samples loaded with COS suggest strongly that the reaction between $\operatorname{COS}$ and primary or secondary amines can be described by the zwitterion reaction mechanism given by reactions 1 and 2. If pseudo-steady-state conditions are assumed for the COS-amine zwitterion concentration, the following expression can be derived for the overall forward reaction rate:

$$
\mathrm{R}_{\mathrm{COS}}=\frac{\left[\mathrm{R}_{2} \mathrm{NH}\right][\mathrm{COS}]}{\frac{1}{k_{2}}+\frac{1}{k_{\mathrm{H}_{2} \mathrm{O}}\left[\mathrm{H}_{2} \mathrm{O}\right]+k_{\mathrm{R}_{2} \mathrm{NH}}\left[\mathrm{R}_{2} \mathrm{NH}\right]}}=k_{\mathrm{app}}[\mathrm{COS}]
$$

with:

$$
k_{\mathrm{H}_{2} \mathrm{O}}=\frac{k_{2} k_{b, \mathrm{H}_{2} \mathrm{O}}}{k_{-1}} \quad k_{\mathrm{R}_{2} \mathrm{NH}}=\frac{k_{2} k_{b, \mathrm{R}_{2} \mathrm{NH}}}{k_{-1}}
$$

Strictly speaking, all bases present in solution will contribute to the deprotonation of the zwitterion (including $\mathrm{OH}^{-}$). However, the contribution of bases other than $\mathrm{H}_{2} \mathrm{O}$ and the amine itself was found to be negligible without loss of accuracy. The observed apparent reaction rate constants were fitted to reaction rate expression 7 by means of a Levenberg-Marquardt fitting procedure. The fitted reaction rate constants are summarized in Table 2.

The zwitterion formation rate constant could be determined only for MEA; for all other amines, the overall reaction rate was determined entirely by the zwitterion deprotonation rate. This zwitterion deprotonation rate was found to be determined primarily by the contribution of amine as can also be concluded from the observed reaction order in amine which was almost 2 for most amines. For DEA at $283 \mathrm{~K}$ and DIPA at $303 \mathrm{~K}$, the contribution of $\mathrm{H}_{2} \mathrm{O}$ to the zwitterion deprotonation rate was too small to determine values for the zwitterion deprotonation rate constants by $\mathrm{H}_{2} \mathrm{O}$.

Both zwitterion deprotonation rate constants were observed to increase with temperature. This temperature influence is given by Eqs. 8 to 10 and by Figures 7 and 8 which show Arrhenius plots for the deprotonation rate constants by amine and water, respectively.

$M E A$ :

$$
\begin{gathered}
k_{\mathrm{R}_{2} \mathrm{NH}}=1.31 \times 10^{-2} \exp \left(\frac{-1,771}{T}\right) \\
k_{\mathrm{H}_{2} \mathrm{O}}=1.35 \times 10^{5} \exp \left(\frac{-8,320}{T}\right)
\end{gathered}
$$

$D G A$ :

$$
\begin{gathered}
k_{\mathrm{R}_{2} \mathrm{NH}}=5.34 \times 10^{5} \exp \left(\frac{-7,346}{T}\right) \\
k_{\mathrm{H}_{2} \mathrm{O}}=4.93 \times 10^{6} \exp \left(\frac{-9,409}{T}\right)
\end{gathered}
$$

Table 2. Fitted Reaction Rate Constants

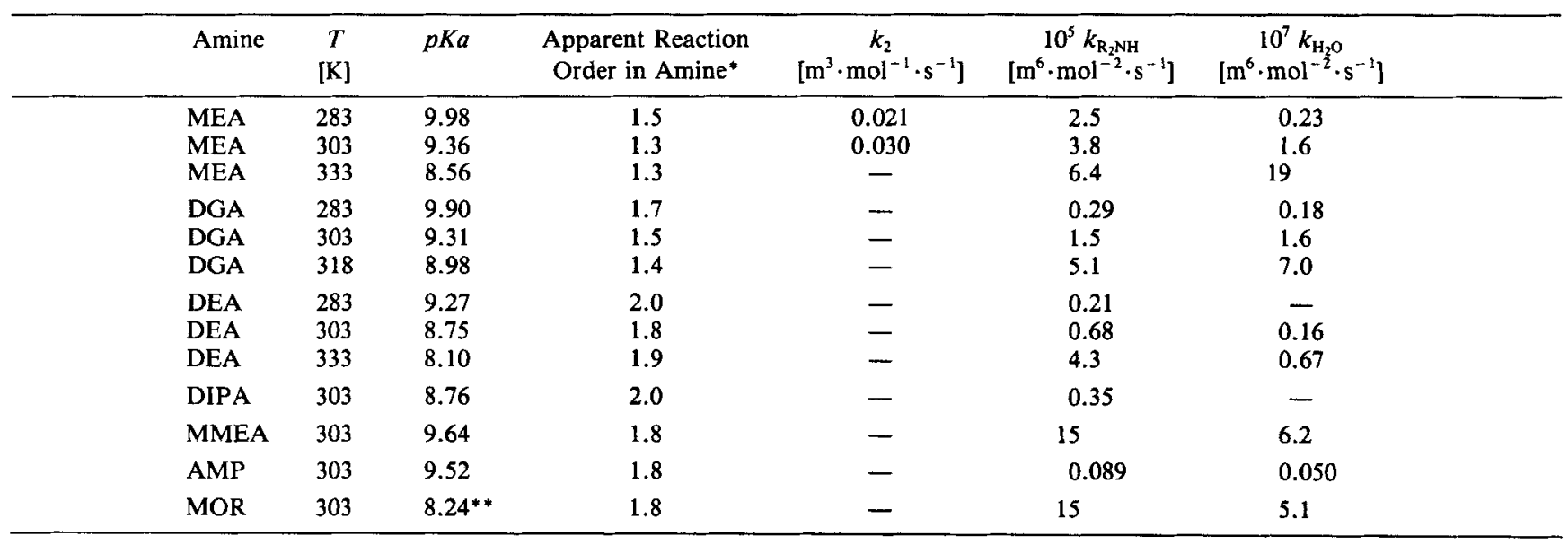

- Approximate error bounds: \pm 0.1 .

- Estimated from $p K a$ value at $298 \mathrm{~K}$. 


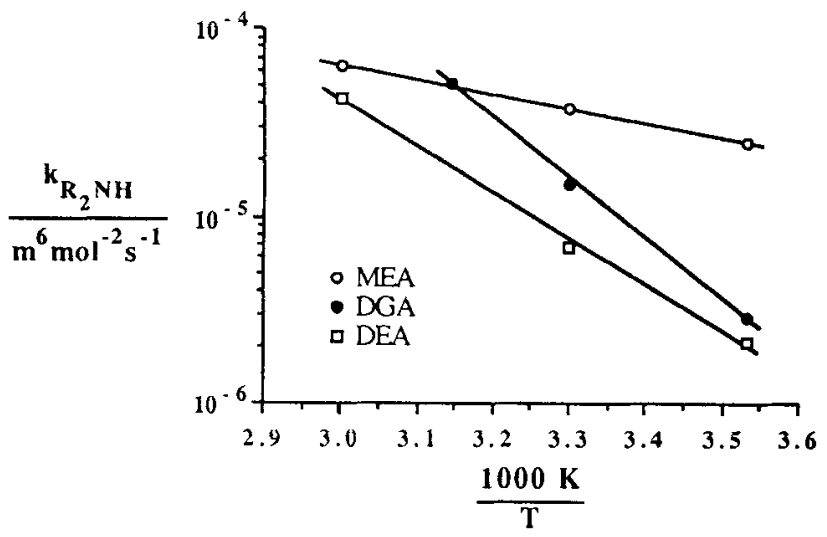

Figure 7. Arrhenius plot for the zwitterion deprotonation rate constants by amine.

$D E A$ :

$$
\begin{gathered}
k_{\mathrm{R}_{2} \mathrm{NH}}=1.16 \times 10^{3} \exp \left(\frac{-5,714}{T}\right) \\
k_{\mathrm{H}_{2} \mathrm{O}}=2.45 \times 10^{5} \exp \left(\frac{-9,199}{T}\right)
\end{gathered}
$$

It is remarkable that the activation temperature for the $k_{\mathrm{R}_{2} \mathrm{NH}}$ shows a large variation for the different amines, whereas the activation temperature for the $k_{\mathrm{H}_{2} \mathrm{O}}$ is almost identical for all three amines. It should be realized, however, that the deprotonation rate constants are a combination of three elementary rate constant (see expression 7) and that therefore no $a$ priori statements can be made concerning the activation temperature for the combined reaction rate constants. For the reaction between $\mathrm{CO}_{2}$ and secondary amines, the deprotonation rate constants were even found to be almost independent of temperature (Littel et al., 1992b).

Sharma (1965) presented kinetic data, obtained in a stirred cell reactor, for various amines at $298 \mathrm{~K}$. However, he carried out experiments only at one amine concentration (1,000 $\mathrm{mol} \cdot \mathrm{m}^{-3}$ ) and assumed that the physical data needed for the interpretation of the kinetic experiments were equal to those in water. Nevertheless, a comparison has been made between the kinetic data reported by Sharma (1965) at $298 \mathrm{~K}$ and the

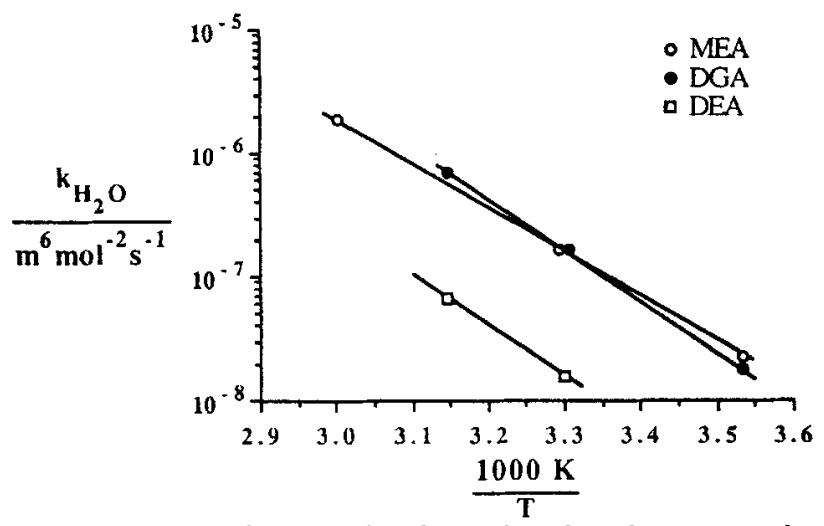

Figure 8. Arrhenius plot for the zwitterion deprotonation rate constants by $\mathrm{H}_{2} \mathrm{O}$.
Table 3. Comparison Between Work of Sharma (1965) and Present Work

\begin{tabular}{lcc}
\hline Amine & $\begin{array}{c}\text { Sharma }(1965)^{*} \\
k_{\text {app }}\left[\mathrm{s}^{-1}\right]\end{array}$ & $\begin{array}{c}\text { Present Work** } \\
k_{\text {app }}\left[\mathrm{s}^{-1}\right]\end{array}$ \\
\hline MEA & 16 & 18.2 \\
DEA & 11 & 7.6 \\
DIPA & 5.6 & 3.5 \\
MMEA & 220 & 182 \\
AMP & 4.5 & 1.1 \\
MOR & 220 & 176 \\
\hline
\end{tabular}

* $T=298 \mathrm{~K},[\mathrm{Am}]=1,000 \mathrm{~mol} \cdot \mathrm{m}^{-3}$

$* T=303 \mathrm{~K},[\mathrm{Am}]=1,000 \mathrm{~mol} \cdot \mathrm{m}^{-3}$

present data at $303 \mathrm{~K}$. Table 3 shows that the agreement between the apparent reaction rate constants at $1,000 \mathrm{~mol} \cdot \mathrm{m}^{-3}$ amine obtained in both works is very acceptable.

Singh and Bullin (1988) carried out kinetic experiments in a continuously operated gas-liquid contactor for aqueous solutions of DGA at temperatures ranging from 307 to $322 \mathrm{~K}$. The progression of the reaction was followed by means of GC analysis of the composition of the amine solutions. They reported a single-order behavior in both $\mathrm{COS}$ and amine concentrations, although it should be noted that their interpretation method did not allow for broken reaction orders. This firstorder behavior in amine is in contradiction with the present work. Also the overall reaction rates presented by Singh and Bullin (1988) are substantially lower than those observed for DGA in the present work. The reasons for these discrepancies are hard to clarify because the work of Singh and Bullin (1988) lacks information on the actually measured reaction rates as a function of amine concentration. Moreover, Singh and Bullin (1988) report that the bruto $\mathrm{CO}_{2}$ concentrations present in solution were found to be negligible, whereas significant bruto concentrations of $\mathrm{H}_{2} \mathrm{~S}$ were observed. Since $\mathrm{H}_{2} \mathrm{~S}$ and $\mathrm{CO}_{2}$ are produced in equal amounts by the disintegration of $\mathrm{COS}$, this discrepancy possibly indicates significant desorption of $\mathrm{CO}_{2}$ which might have obscured the kinetic experiments of Singh and Bullin (1988).

The present kinetic data obtained for the reaction between $\mathrm{COS}$ and primary or secondary amines can be compared to the kinetic data for $\mathrm{CO}_{2}$ as reported by Versteeg and van Swaaij (1988a), Bosch et al. (1990), and Littel et al. (1991b). For the nonhindered alkanolamines (MEA, DGA, DEA, DIPA, and MMEA), the observed reaction rates for COS are in general roughly a factor 100 lower than the reaction rates for $\mathrm{CO}_{2}$. The reaction order in amine for COS, however, is usually higher than that for $\mathrm{CO}_{2}$, indicating that the overall reaction rate for $\mathrm{COS}$ is much more limited by the zwitterion deprotonation rate. The zwitterion deprotonation rate for the COSamine zwitterion was observed to increase considerably with increasing temperature, whereas the deprotonation rate of the $\mathrm{CO}_{2}$-amine zwitterion appears to be almost independent of temperature (Littel et al., 1991b). Since all bases present in solution will contribute to the zwitterion deprotonation, the application of blends of tertiary and secondary or primary amines might be beneficial for selective COS removal. Also relatively high amine concentrations, which lead to higher ratios of $\operatorname{COS}$ and $\mathrm{CO}_{2}$ solubilities, seem to promote $\mathrm{COS}$ removal.

Sterically hindered secondary amines like AMP appear to be suitable for selective $\mathrm{H}_{2} \mathrm{~S}$ removal (Sartori et al., 1987), 
However, the difference between the reaction rates of COS and of $\mathrm{CO}_{2}$ with aqueous AMP solutions (Bosch et al., 1990) is substantially larger than for the nonhindered amines, indicating that sterically hindered secondary amines are probably not suitable for selective COS removal. The cyclic amine MOR reacts relatively fast with $C O S$ in relation to its basic strength, but it was found to react fast also with $\mathrm{CO}_{2}$ (Littel et al., 1991b).

\section{Conclusions}

The reaction between $\mathrm{COS}$ and aqueous solutions of primary and secondary amines has been studied by means of the stirred cell technique. Kinetic experiments at temperatures ranging from 283 to $333 \mathrm{~K}$ were carried out with MEA, DGA, DEA, DIPA, MMEA, AMP, and MOR.

All kinetic experiments could be described by a zwitterion mechanism similar to the zwitterion mechanism proposed by Caplow (1968) for the reaction between $\mathrm{CO}_{2}$ and secondary amines. Analysis of concentrated amine solutions at high COS concentrations by means of various analytical techniques confirmed the conclusions from the kinetic experiments. For all amines except for MEA, the overall reaction rate was found to be entirely determined by the zwitterion deprotonation rate.

Solutions of MEA and MMEA were found to be susceptible to amine degradation and seem therefore not suitable for COS removal. Also solutions of sterically hindered secondary amines like AMP seem to be unsuited to selective COS removal due to the very low reaction rates of AMP with COS in comparison to the reaction rates between $\mathrm{CO}_{2}$ and AMP. For nonhindered amines, the $\mathrm{COS}$ reaction rate with respect to the $\mathrm{CO}_{2}$ reaction rate is promoted by higher amine concentrations and higher temperatures.

\section{Acknowledgment}

These investigations were supported by the Koninklijke/Shell Laboratorium, Amsterdam, The Netherlands. We also acknowledge W. Leppink for the construction of the experimental setup and C. van der Beek, M. van Dijk, W. Lengton, and H. ter Maat for their part in the experimental work.

\section{Notation}

$$
\begin{aligned}
D & =\text { diffusivity, } \mathrm{m}^{2} \cdot \mathrm{s}^{-1} \\
E & =\text { enhancement factor } \\
E^{\infty 0} & =\text { maximum enhancement factor }(\mathrm{Eq} \cdot 6) \\
H a & =\text { Hatta number }(\mathrm{Eq} \cdot 5) \\
J & =\text { molar flux, mol } \cdot \mathrm{m}^{-2} \cdot \mathrm{s}^{-1} \\
k_{\mathrm{app}} & =\text { apparent psuedo-first-order reaction rate constant, } \mathrm{s}^{-1} \\
k_{\mathrm{ov}} & =\text { overall psuedo-first-order reaction rate constant, } \mathrm{s}^{-1} \\
k_{2} & =\text { zwitterion formation rate constant, } \mathrm{m}^{3} \cdot \mathrm{mol}^{-1} \cdot \mathrm{s}^{-1} \\
k_{\mathrm{R}_{2} \mathrm{NH}} & =\text { zwitterion deprotonation constant by amine, } \\
k_{\mathrm{H}_{2} \mathrm{O}} & =\text { zwitterion deprotonation constant by water, } \mathrm{m}^{6} \cdot \mathrm{mol}^{-2} \cdot \mathrm{s}^{-1} \\
k_{L} & =\text { liquid phase mass transfer coefficient, } \mathrm{m} \cdot \mathrm{s}^{-1} \\
m & =\text { dimensionless solubility, mol } \cdot \mathrm{mol}^{-1} \\
P & =\text { pressure, Pa } \\
R & =\text { ideal gas constant, } 8.314 \mathrm{~J} \cdot \mathrm{mol}^{-1} \cdot \mathrm{K}^{-1} \\
T & =\text { temperature, T }
\end{aligned}
$$

\section{Greek letters}

$$
\eta=\text { viscosity, } \mathrm{Pa} \cdot \mathrm{s}
$$

\section{Amine abbreviations}

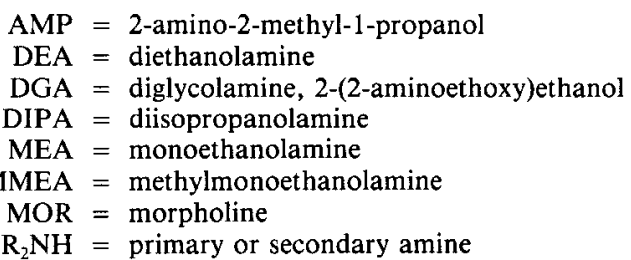

\section{Literature Cited}

Berlie, E. M., J. W. Estep, and F. J. Ronicker, "Preventing MEA Degradation," Chem. Eng. Prog., 61, 82 (1965).

Blauwhoff, P. M. M., G. F. Versteeg, and W. P. M. van Swaaij, “A Study on the Reaction Between $\mathrm{CO}_{2}$ and Alkanolamines in Aqueous Solutions," Chem. Eng. Sci., 39, 207 (1984).

Bosch, H., G. F. Versteeg, and W. P. M. van Swaaij, "Kinetics of the Reaction of $\mathrm{CO}_{2}$ with the Sterically Hindered Amine 2-Amino2-Methylpropanol at 298 K," Chem. Eng. Sci., 45, 1167 (1990).

Caplow, M., "Kinetics of Carbamate Formation and Breakdown," J. Amer. Chem. Soc., 90, 6795 (1968).

Danchwerts, P. V., "The Reaction of $\mathrm{CO}_{2}$ with Ehtanolamines," Chem. Eng. Sci., 34, 443 (1979).

Ewing, S. P., D. Lockshon, and W. P. Jencks, "Mechanism of Cleavage of Carbamate Anions," J. Amer. Chem. Soc., 102, 3072 (1980).

Kohl, A. L., and F. C. Riesenfeld, Gas Purification, Gulf Publishing, Houston (1985).

Littel, R. J., G. F. Versteeg, and W. P. M. van Swaaij, "Kinetics of $\mathrm{CO}_{2}$ with Primary and Secondary Amines in Aqueous Solutions: I. Zwitterion Deprotonation Kinetics for DEA and DIPA in Aqueous Blends of Alkanolamines," Chem. Eng. Sci., in press (1992a).

Littel, R. J., G. F. Versteeg, and W. P. M. van Swaaij, "Kinetics of $\mathrm{CO}_{2}$ with Primary and Secondary Amines in Aqueous Solutions: II. Influence of Temperature on Zwitterion Formation and Deprotonation Rates," Chem. Eng. Sci., in press (1992b).

Littel, R. J., G. F. Versteeg, and W. P. M. van Swaaij, "Solubility and Diffusivity Data for the Absorption of $\mathrm{COS}, \mathrm{CO}_{2}$, and $\mathrm{N}_{2} \mathrm{O}$ in Amine Solutions," J. Chem. Eng. Data, in press (1992c).

Millican, R. J., M. Angelopoulos, A. Bose, B. Riegel, D. Robinson, and C. K. Wagner, "Uncatalyzed and General Acid Catalyzed Decomposition of Alkyl Xanthates and Monothiocarbonates in Aqueous Solutions," J. Amer. Chem. Soc., 105, 3622 (1983).

Pearce, R. L., J. L. Arnold, and C. K. Hall, "Studies Show Carbonyl Sulfide Problem," Hydroc. Proc. \& Petr. Ref., 40, 121 (1961).

Philipp, B., and H. Dautzenberg, "Kinetische Untersuchungen zur Bildung und Zersetzung von Monothiocarbonat in wässrige Lösung," Z. Phys. Chem., 229, 210 (1965).

Rahman, M. A., R. N. Maddox, and G. J. Mains, "Reactions of Carbonyl Sulfide and Methyl Mercaptan with Ethanolamines," Ind. Eng. Chem. Res., 28, 470 (1989).

Sartori, G., W. S. Ho, D. W. Savage, G. R. Chludzinski, and S. Wiechert, "Sterically-Hindered Amines for Acid-Gas Absorption," Sep. Purif. Meth., 16, 171 (1987).

Sharma, M. M., "Kinetics of Reactions of Carbonyl Sulfide and Carbon Dioxide with Amines and Catalysis by Brönsted Bases of the Hydrolysis of COS," Trans. Farad. Soc., 61, 681 (1965).

Singh, M., and J. A. Bullin, "Determination of Rate Constants for the Reaction Between Diglycolamine and Carbonyl Sulfide," Gas Sep. \& Purif., 2, 131 (1988).

Thompson, H. W., C. F. Kearton, and S. A. Lamb, "The Kinetics of the Reaction Between Carbonyl Sulfide and Water," J. Chem. Soc., 1033 (1935).

Versteeg, G. F., and W. P. M. van Swaaij, "On the Kinetics Between $\mathrm{CO}_{2}$ and Alkanolamines Both in Aqueous and Nonaqueous Solutions: I. Primary and Secondary Amines," Chem. Eng. Sci., 43, 573 (1988a).

Versteeg, G. F., and W. P. M. van Swaaij, "Solubility and Diffusivity of Acid Gases $\left(\mathrm{CO}_{2}, \mathrm{~N}_{2} \mathrm{O}\right)$ in Aqueous Alkanolamine Solutions," J. Chem. Eng. Data, 33, 29 (1988b).

Versteeg, G. F., and M. H. Oyevaar, "The Reaction Between $\mathrm{CO}_{2}$ and Diethanolamine at $298 \mathrm{~K}$," Chem. Eng. Sci., 44, 1264 (1989). 